\title{
MODOS DE ENDEREÇAMENTO E A RECEPÇÃO DO TEXTO CINEMATOGRÁFICO
}

\author{
Way of Addressing and the Reception the Cinematographic Text
}

\author{
LílianRodrigues da Cruz ${ }^{1}$ \\ Neuza Maria de Fátima Guareschi ${ }^{2}$
}

\section{Resumo}

O campo dos estudos culturais inovou ao afirmar que toda ação social é cultural e que todas as práticas sociais comunicam um significado, ou seja, são práticas de significação (Hall, 2000). No campo dos estudos culturais, o significado de um filme é produzido em relação ao público. Dessa forma, situando o cinema como uma mídia que ocupa um espaço na subjetivação dos sujeitos, este trabalho concentra-se na experiência cinematográfica, focalizando os sentidos produzidos por espectadores e espectadoras ao assistirem a um filme. Objetiva entender a relação entre o texto de um filme e a produção de sentidos pelo espectador e pela espectadora. Na tentativa de elucidar tais questões, entrevistamos dez sujeitos adultos com o hábito de ir ao cinema. Podemos dizer que o espectador nunca é quem o filme pensa que ele é. Assim como não existe um único modo de endereçamento em um filme. A posição que o espectador assume em relação a um filme, e a partir da qual ele dá sentido ao filme, muda dependendo dos conflitantes modos de endereçamento que possam estar disponíveis. Salientamos que a proposta deste trabalho não é conhecer o endereçamento dos filmes, até porque seria bastante difícil conhecê-los, pois a relação entre a indústria cinematográfica e o público é bastante complexa. A discussão aponta para variadas posições de sujeito no que se refere ao modo de endereçamento.

Palavras-chave: Texto cinematográfico; Estudos culturais; Modo de endereçamento.

Psicóloga, Doutora em Psicologia (PUCRS), Docente do Departamento de Psicologia e do Mestrado em Letras na Universidade de Santa Cruz do Sul (UNISC). Santa Catarina, SC.e-mail: liliancruz2@terra.com.br

2 Psicóloga, Doutora em Educação (University of Wisconsin - Madison), Docente do Departamento de Psicologia e do Programa de Pós-Graduação em Psicologia (PUCRS), Coordenadora do Grupo de Pesquisa Estudos Culturais e Teorias Contemporâneas. Rio Grande do Sul, RS.e-mail:nmguares@pucrs.br 


\section{Abstract}

The field of the cultural studies has innovated in affirming that every social action is cultural and that every social practice communicates a meaning, that is, they are practices of significance(Hall, 2000). In the field of the cultural studies, the meaning of a movie is produced in relation to the public. Thus, pointing out the cinema as a media that occupies a space on the subjection of the citizens, this work is centered on the cinematographic experience, focusing the sense produced by the spectators when watching a film. This work also aims to understand the relation between the text of a film and the production of sense by the spectator. In the attempt to elucidate such questions, we have interviewed ten adult subjects with the habit of going to the cinema. It is possible to say that the spectator never is who the movie guesses he/she is. In the same way that there is not only one way of addressing in a movie. The position taken by the spectator in relation to a movie, and from where he/she gives meaning to the movie, changes depending on the conflicting ways of addressing that may be available. We highlight that this work's proposal is not to know the addressing of the movies, even because it would be very difficult to know them once the relationship between the cinematographic industry and the public is very complex. The discussion points out to several positions of the subject concerning to the way of addressment.

Keywords: Cinematographic text; Cultural studies; Way of addressing.

\section{Apresentando a questão}

O campo dos estudos culturais inovou ao afirmar que toda ação social é cultural e que todas as práticas sociais comunicam um significado, ou seja, são práticas de significação (Hall, 2000). Nesse sentido, parece não haver mais a possibilidade de determinar a procedência de nossos conhecimentos e práticas culturais, pois as características que nos constituem se mesclam, se fragmentam, se associam. Podemos dizer que somos seres híbridos, constituídos por múltiplas e diferentes identidades. Para Fabris (2000), nessas mudanças que estão acontecendo, as instituições tidas como tradicionais, como a família, a igreja, a escola, parecem estar perdendo espaço nos processos de subjetivação, quando surgem novas instâncias que vêm contribuir nesse processo, como é o caso da mídia. Aquelas instituições passaram a ser ressignificadas pela própria mídia. Hall (2000) é um dos autores que desenvolve uma análise dessas transformações culturais e sociais no processo de constituição das identidades, bem como Fischer (1999), ao apontar que a construção das identidades não é pertinente apenas ao campo da psicologia, pois a mídia é um veículo de exposição importante de modos de vida, ocupando um lugar decisivo no processo de construção de identidades.
Dessa forma, situando o cinema como uma mídia que ocupa um espaço na subjetivação dos sujeitos, este trabalho concentra-se na experiência cinematográfica, focalizando os sentidos produzidos por espectadores e espectadoras ao assistirem a um filme. Objetiva entender a relação entre o texto de um filme e a produção de sentidos pelo espectador e pela espectadora. ${ }^{3}$ Iniciamos contextualizando o cinema no campo dos estudos culturais, bem como a tensão nos modos de endereçamento dos filmes. Finalizamos tecendo algumas considerações a partir das narrativas dos sujeitos entrevistados.

\section{Estudos culturais e cinema}

A partir dos estudos culturais, Turner (1997) sugere que o cinema seja estudado como entretenimento, narrativa, apresentando-o como prática social e buscando compreender sua produção, consumo, prazer e significados. Assim, o significado de um filme é produzido em relação ao público, nunca independente dele. Dessa forma, podemos inferir que o público encontra uma variedade de significados em qualquer texto cinematográfico, pois esses não são fixos, mas mutáveis. Um dos resultados da ruptura entre os estudos sobre cinema e uma tradição predominantemente estética é o abandono da idéia de

\footnotetext{
Para facilitar a leitura, procuraremos alternar no texto entre o masculino e o feminino.
} 
que num filme havia um núcleo de significado que o público devia descobrir (Bruschi, 2002). Os trabalhos que seguem essa abordagem caracterizam o cinema como meio de comunicação e prática social, em que cada espectador confere a cada texto cinematográfico um significado único (Turner, 1997).

Contudo, o cinema apresenta uma linguagem com morfologia e sintaxe próprias. Os efeitos de montagem, enquadramento, iluminação e edição de som que influenciam nas infinitas possibilidades de narrativas são possíveis dentro de um processo de produção industrial. Furtado (1992) é categórico ao afirmar que o cinema é um trabalho de equipe e, ainda que quase tudo no cinema seja mentira - pois o movimento, real aos nossos sentidos, não existe - tudo não passa de um truque que envolve instrumentos mecânicos e óticos de alta precisão, como o ritual mágico da sala escura e um espectador predisposto a ser enganado. Podemos dizer que o cinema possui um "poder de convencimento ${ }^{4}$ desde os primórdios, quando os espectadores de Lumière ${ }^{5}$ esconderam-se debaixo de suas cadeiras, apavorados, diante do trem que se arremessava contra eles".

A forma como os filmes são processados pelo público é o que os torna ainda mais reais e o que os leva a ter um efeito ainda mais poderoso. No escuro, as imagens levam o espectador para fora da própria realidade e para dentro do filme, até fundir as duas (Gabler, 1999). O mesmo autor cita Mark Edmundson para definir outra característica do cinema: a transcendência fácil. Os filmes precisam apenas que nos deixemos ser transportados. Para Turner (1997), o longa realista tem características específicas que aumentam o seu poder de sedução, pois cria um mundo que é o mais identificável possível. A conseqüência é que o público entende isso recorrendo a analogias entre o mundo do filme e seu próprio universo. No entanto, isso ocorre porque as tecnologias da produção cinematográfica ficam ocultas.

Dessa forma, a grande força de comunicação do cinema reside no fato de que, quando o público está sentado na sala escura do cinema, "esquece" que está vendo um filme. Assim, o espectador tem a possibilidade de entrar em uma relação particular com a história e o sistema de imagem do filme. Ellsworth (2001) aprofunda tal questionamento dizendo que, se for possível compreender qual é a relação entre o texto de um filme e a experiência do espectador, então há a possibilidade de mudar ou influenciar - até mesmo controlar - a resposta do espectador, produzindo um filme de uma forma particular.

\section{Texto cinematográfico $e$ modo de endereçamento}

Os teóricos do cinema desenvolveram a noção de "modo de endereçamento" para lidar com essas grandes questões que atravessam os estudos de cinema, a crítica de arte, a lingüística, a sociologia, a psicologia, a história e a educação. Questões como a relação entre o texto de um filme e a experiência de uma espectadora (Donald, 1991). Dessa forma, o modo de endereçamento de um filme está relacionado com a necessidade de endereçar alguma comunicação, texto ou ação para alguém. Ellsworth (2001) afirma que os interesses comerciais dos produtores de um filme têm a ver com o desejo de controlar, como e a partir de onde o espectador ou a espectadora lê o filme. Tem a ver com o atrair o espectador a uma posição particular de conhecimento para com o texto, uma posição de coerência, a partir da qual o filme funciona, adquire sentido, dá prazer e agrada dramática e esteticamente.

Lembremos que entre a redação do roteiro e a exibição, os filmes passam por muitas transformações. Entretanto, a maioria das decisões sobre a narrativa estrutural de um filme é feita à luz de pressupostos conscientes e inconscientes sobre "quem" são seus públicos, o que eles querem, como eles vêem filmes, o que os faz chorar ou rir, o que eles temem e quem eles pensam que são, em relação a si próprios, aos outros e às tensões sociais e culturais do momento.

Dessa forma, os produtores de filmes fazem muitas suposições e têm muitos desejos conscientes e inconscientes sobre o tipo de pessoa para a qual seu filme é endereçado e sobre as posições e identidades sociais e culturais que seu público deve

\footnotetext{
4 Essa expressão é utilizada na obra “A linguagem secreta do cinema”, de Jean-Claude Carrière, 2006.

5 “A chegada do trem na estação" foi projetada em 1896, na França, sob direção de Louis Lumière. Descrição da "vista”: uma ferrovia, em perspectiva diagonal. Na plataforma, passageiros endomingados esperam. Um carregador avança em direção à câmara. Do fundo do campo, surge uma locomotiva, que vem parar à esquerda da tela. Descem umas pessoas de um compartimento, entre as quais uma senhora vestindo uma pelerine. Outras pessoas preparam-se para subir no trem, entre as quais um homem com uma trouxa (Beylie, 1991).
} 
ocupar. O modo de endereçamento se parece mais com a estrutura narrativa do filme do que com seu sistema de imagem. Tal como a história ou a trama, o modo de endereçamento não é visível. Além disso, ele não é um momento visual ou falado, mas uma estruturação - que se desenvolve ao longo do tempo - das relações entre o filme e seus espectadores (Ellsworth, 2001).

A autora assinala que, em outro momento, os teóricos do cinema começaram a ver o modo de endereçamento menos como algo que está em um filme e mais como um evento que ocorre em algum lugar entre o "social" e o "individual". Assim, o evento do endereçamento ocorre num espaço que é social/psíquico entre o texto fílmico e os usos que a espectadora faz dele. Passar a compreender o modo de endereçamento como um evento e deixar de localizá-lo no interior do texto de um filme é uma maneira de enfocá-lo no campo dos estudos culturais. Centrar as análises nos fenômenos culturais significa assumir que a cultura é uma das condições constitutivas de existência de toda prática social, que toda prática tem uma dimensão cultural (Veiga-Neto, 2000).

Escosteguy (2001) salienta que vincular os estudos culturais e a comunicação significa que a investigação da cultura mediática inclui tanto os meios como os produtos e as práticas culturais. Refere-se, portanto, tanto à natureza e à forma dos produtos simbólicos quanto ao circuito de produção, distribuição e consumo. Dessa maneira, no eixo comunicação e cultura está inserida uma concepção de sociedade com variadas possibilidades de dominação e resistência. A cultura tanto se engaja na reprodução das relações sociais quanto na abertura de possíveis espaços para mudança.

Podemos dizer, então, que o espectador nunca é (totalmente) quem o filme pensa que ele é. Assim como não existe um único e unificado modo de endereçamento em um filme. A posição que o espectador "assume" em relação a um filme, e a partir da qual ele dá sentido ao filme e dele extrai prazer, muda drasticamente, dependendo dos conflitantes modos de endereçamento que possam estar disponíveis. Ellsworth (2001) enfatiza que a relação entre a forma como os textos cinematográficos endereçam seu público e a forma como os espectadores lêem os filmes não são nítidas ou puras, muito menos lineares. $\mathrm{O}$ espaço da diferença entre o endereçamento e a resposta é um espaço social, formado e informado por conjunturas históricas de poder e de diferença social e cultural. O espaço da diferença entre o endereçamento e a resposta é um espaço que carrega atividades inconscientes imprevisíveis.

Assim, considerando a emergência dos estudos culturais, de teorizações sobre a possibilidade de posicionamentos sociais fluidos, múltiplos e estratégicos, podemos atualizar o conceito de modo de endereçamento, ressaltando o jogo de poder da diferença que estão aí implicados. Um exemplo interessante refere-se ao filme "Titanic". ${ }^{6}$ Bruschi (2002) mostra que ocorreu uma espécie de conflito de endereçamento entre os produtores executivos do filme e o diretor James Cameron. A indústria pretendia endereçar para o público masculino (principalmente adolescentes) apostando na tragédia e na ação. Por outro lado, Cameron queria contar uma trágica história de amor. Foi uma legítima batalha entre o artista e a indústria. "Titanic" ficou como seu criador queria, ganhando a briga com o estúdio, uma vez que o filme foi sucesso indiscutível de público. A partir disso, a indústria cinematográfica começou a prestar mais atenção a uma nova fatia de mercado: as adolescentes. Foram elas e as jovens as responsáveis pelo recorde de bilheteria do filme. Essas costumam rever o filme mais de uma vez e, ao contrário dos adolescentes, que vão ao cinema com um ou dois amigos, preferem ir em grupos maiores.

Outro exemplo a considerar refere-se ao filme "Thelma e Louise". ${ }^{7}$ Esse filme foi projetado num preview para testar duas alternativas de finais: o que existe e outra versão em que Thelma e Louise fogem. O filme sofreu duras críticas por sua alegada defesa da "violência feminina contra os homens", contudo foi um sucesso de bilheteria. O filme tocou em pontos sensíveis de um grande número de espectadoras. Teria sido um erro de endereçamento? Ellsworth (2001) acredita que o endereçamento

\footnotetext{
O filme "Titanic" mistura ficção e realidade para contar a biografia do desastre. Conta a história de uma jovem americana de 17 anos que embarca no navio com seu noivo. Lá, a jovem conhece um passageiro da terceira classe, com quem inicia um romance (Sinopse feita pela primeira autora).

O filme "Thelma e Louise" conta a história de duas amigas, uma garçonete de meia-idade e uma jovem dona de casa, que resolvem deixar tudo para trás num fim de semana. No caminho, envolvem-se em encrencas e até em delitos. Acabam sendo perseguidas pela polícia (Sinopse feita pela primeira autora).
} 
navega na escolha entre o pano de fundo de formas emergentes, de representar e responder à situação das mulheres. "E é este caráter de acontecimento histórico e cultural do endereçamento que faz com que se torne impossível que os produtores de filmes possam controlá-lo inteiramente da forma como eles controlam, por exemplo, a iluminação". Como argumenta a autora, é dessa forma que o modo de endereçamento excede as fronteiras do próprio texto do filme e extravasa para as conjunturas históricas da produção e da recepção do filme. O modo de endereçamento envolve história e público, expectativa e desejo.

Donald (1991) argumenta que "no próprio centro da vida psíquica", a identidade plena e completa é não apenas impossível, mas que nós, na verdade, resistimos a ela. Existe uma resistência à identidade - ao perfeito ajuste entre, de um lado, as normas sociais e, de outro, a forma como nós sentimos e o que queremos. Essa resistência está ligada a um sentimento freqüentemente inconsciente de que nós somos (de que devemos ser) mais do que os "eus" que nossas culturas, nossas escolas, nossos governos, nossas famílias, nossas normas sociais e nossas expectativas estão nos oferecendo ou exigindo que sejamos. De fato, se fosse possível obter ajustes perfeitos entre as relações sociais e a realidade psíquica, entre o eu e a linguagem, nossas subjetividades e nossas sociedades seriam fechadas.

Nesse sentido, o presente estudo concentrase nas potencialidades da experiência cinematográfica, focalizando os sentidos produzidos por espectadores e espectadoras ao assistirem a um filme. Como o modo de endereçamento de um filme posiciona seu público frente à produção de modos de vida? Essa experiência parece estar relacionada com as diferentes posições de sujeito. Segundo Bernardes e Guareschi (2003), os textos culturais da mídia oferecem uma riqueza de posição de sujeito, uma vez que diferentes articulações, diferentes práticas de significação os envolvem de diferentes maneiras, segundo os discursos que os interpelam, bem como os contextos particulares dos quais emergem.

\section{Contextualizando a investigação}

Como os sujeitos escolhem os filmes para assistir e quais são suas expectativas? Que sentidos são produzidos pelos sujeitos a partir de textos fílmicos? Na tentativa de elucidar tais questões, entrevistei dez sujeitos adultos com o hábito de ir ao cinema. Identifico os sujeitos quanto ao nome (fictício) e à profissão: Beatriz, jornalista; Paula, psicóloga; João, neurologista; Sandra, tradutora; Marcos, químico; Jane, geneticista; Pedro, arquiteto; Lucas, publicitário; Norma, filósofa, e Magda, assistente social. Os temas explorados por meio de entrevista semi-estruturada foram os motivos para ir ao cinema, as expectativas ao assistir a determinado filme, tipo de filme que mais aprecia, relação que estabelece com as personagens, analogias entre o mundo do filme e o universo do sujeito, significados em assistir a determinados filmes, dentre outros temas que emergiram no decorrer da entrevista. Todas as entrevistas foram realizadas pela primeira autora, gravadas em audiotape e, posteriormente, transcritas. A análise dos depoimentos consistiu de três etapas, conforme sugere Gomes (1997). As narrativas foram demarcadas por meio do método fenomenológico (descrição, redução e interpretação). A análise fenomenológica das entrevistas constituiu-se em transformar e reorganizar descritivamente as informações, sem alterar as características primárias. Mantivemos, inclusive, alguns trechos literais para que os leitores pudessem perceber melhor as idiossincrasias de cada sujeito.

\section{Tecendo algumas considerações}

Afinal, o que o espectador deseja ao despender duas horas assistindo a um filme? As entrevistas apontam que o desejo fundamental é a emoção. Independente do gênero do filme, a emoção é o ingrediente fundamental que os espectadores buscam. Emoção no sentido lato, podendo significar também o prazer estético de determinadas imagens, ou mesmo a narratividade do filme. Lucas, Jane e Norma lembram com exatidão a primeira vez em que entraram no cinema. Cada um deles consegue descrever o contexto desta experiência, bem como os sentimentos suscitados. Embora o significado seja único para cada um, eles o descrevem como um marco em suas vidas.

Paula diz que sua expectativa ao assistir determinado filme é emocionar-se, é sentir-se envolvida na história. Acrescenta que gosta do drama psicológico, pois revela os sentimentos profundos das pessoas. Já Marcos relata que ir ao cinema lhe 
dá prazer. Muitas vezes gostaria de que algumas pessoas vissem um determinado filme porque ele acredita que entenderiam melhor seus sentimentos. Ainda em relação à emoção e à expectativa, Beatriz fala: "Os filmes ótimos são aqueles que, quando você sai de lá, não é mais a mesma pessoa que entrou. Então, é esta a minha expectativa em ir ao cinema. É maravilhosa a sensação de sair de uma maneira um pouco diferente daquela que você entrou". Continua relatando que os filmes falam da vida das pessoas, de aspectos da realidade e é isso que a faz apaixonada pelo cinema.

Tais expectativas e emoções são entendidas por Turner (1997) por prazeres que encontramos naquilo que nos é familiar. Há o prazer de confirmar, pelo conhecimento que se tem do filme, a qualidade de membro da cultura. Para o autor, são muitos os prazeres envolvidos na decisão do público de ver um filme e na relação que as pessoas têm com o filme quando o vêem. São prazeres sociais, culturais, dos quais as pessoas se apropriam para seu próprio uso, mas que de modo algum têm origem individual. São prazeres oferecidos também por outras práticas sociais dentro da cultura e, portanto, revelam como a prática social do cinema está embutida em outras práticas, em outros sistemas de significado.

Nesse sentido, Lucas refere que ir ao cinema é um ritual que inicia ao sair de casa em direção ao cinema, passando por estacionar o carro e, por fim, comprar o ingresso e entrar na sala. Diz que a sala de espera é o período de ambientação. Afirma que há, nos espectadores, a vontade de compartilhar da história, por isso as pessoas não gostam de ir ao cinema sozinhas. Ele percebe o cinema como um ato social, com características integrativas. Magda diz que o bom é sair de casa para ir ao cinema, onde outras pessoas também ficam esperando, têm o mesmo objetivo. A gente faz um contrato com a tela, com a história que está se desenrolando.

Alguns informantes esclarecem que o próprio ritual que envolve uma sessão de cinema, a sala escura, o grupo de pessoas com o mesmo objetivo, a tela grande, são aspectos importantes que propiciam ao espectador sair de sua realidade e se entranhar na história que está sendo narrada. Essa forte relação que se estabelece entre espectador e filme aproxima o espectador da ação cinematográfica. Assim, o espectador encontra-se coexistindo com a ação cinematográfica, enquanto a tela, como um espelho, sugere-lhe refletir. Essa capacidade de se entranhar na história só é possível porque o filme descreve fragmentos da experiência como as repressões profundas e as emoções intensas que, ao contrário da vida real, são sentidas e vividas com tranqüilidade. Essa "tranqüilidade" capacita o espectador a apropriar-se do mundo do filme e a fazer analogias com seu mundo. O filme, para mim, não termina quando acaba a projeção, ele continua vivo dentro de mim (Beatriz). Eu faço o contrário, puxo os filmes para minha vida. Vou ao encontro dos filmes e trago eles para o meu cotidiano. A impressão é que saio um pouco diferente, mais rica para a vida (Norma). Parece que tô dentro da história. Estou participando, eu não existo mais como eu, mas sou aquela personagem, eu me envolvo com a personagem. Eu tenho muita facilidade de me projetar na personagem, quer dizer, eu sempre me identifico com uma personagem e acabo projetando isso nela. E ai é muito fácil, eu não sou mais a Sandra, eu sou outra coisa, eu sou a personagem que está na tela (Sandra).

Outra fala interessante é a de Marcos, quando afirma que se vê sempre entre dois opostos. Então conta que já estava convicto de que iria comprar um apartamento quando assistiu a "Um lugar no mundo". ${ }^{8}$

A partir deste ficou pensando novamente em morar longe da urbanização. Verbaliza: Mas afinal de contas, o que tu quer ser, quem é o Marcos? Eu desenvolvi uma admiração grande pelo personagem, me espelhei nele. Às vezes me identifico tanto que considero um problema, tendo que levar para a terapia.

Neste recorte, podemos visualizar o processo de fragmentação da identidade do sujeito pós-moderno. Para Hall (1997), culturas são os sistemas ou códigos de significado que os seres humanos utilizam para interpretar, organizar e regular sua conduta, enfim, para dar sentido às próprias ações assim como às ações dos outros. A partir dessa posição, o autor afirma que não se pode

\footnotetext{
O filme "Um lugar no mundo" conta a história de um casal de intelectuais argentinos que estão "refugiados" numa comunidade rural. Eles tentam organizá-la a partir de conceitos mais humanos. O homem organiza uma cooperativa com os pequenos produtores de lã de ovelha. Sua esposa é médica e atende à comunidade pobre, conscientizando a população da importância de medidas profiláticas para uma boa saúde. O filho do casal é um adolescente que ajuda o pai a alfabetizar as crianças da região. O filme enfatiza a luta do casal na construção de um mundo mais justo, apresentando um ambiente bucólico e pleno de nostalgia (Sinopse feita pela primeira autora).
} 
mais pensar numa identidade essencial, mas em várias identidades, (trans)formadas continuamente em relação ao modo como se é representado ou interpelado pelos sistemas culturais ao redor, podendo até ser contraditórias ou não resolvidas. Assim, "à medida que os sistemas de significação e representação cultural se multiplicam, somos confrontados por uma multiplicidade desconcertante e cambiante de identidades possíveis, com cada uma das quais poderíamos nos identificar - ao menos temporariamente" (Hall, 2000).

Por outro lado, João diz:

Às vezes me identifico ao contrário. Por exemplo, eu me considero uma pessoa contrária à violência de qualquer tipo. Sou visceralmente contra a violência. Então, quando vejo um filme nazista, ou de/sobre o nazismo, é importante eu perceber porque sou antinazista. A imagem me ajuda a revelar meus próprios sentimentos, minha ideologia.

Como notamos, muitas vezes, a identificação não ocorre com um personagem, mas com uma dada situação, identificando no personagem uma expressão/ação com que ele não concorda na humanidade. Outro exemplo semelhante é o de Marcos, radicalmente contra o racismo, enoja-se ao assistir a um filme com ideologia favorável ao racismo; também se sente impotente frente a situações homofóbicas que determinados filmes apresentam.

Importante explicitar que na perspectiva dos Estudos Culturais o conceito de identidade é pensado em relação à diferença. Assim, identidade e diferença estão sujeitas a vetores de força, a relações de poder, onde "a afirmação da identidade e a marcação da diferença implicam, sempre, as operações de incluir e excluir" (Silva, 2000). Das lutas por imposições e negociações de sentidos, nascem as políticas de identidades: organizações de contestação que não se fazem pelo igual, mas pela diferença, não se caracterizam pela luta da imposição de uma identidade, mas "constituem-se na diferença, naquilo que não o são, não em termos materiais, mas em termos discursivos" (Guareschi, 2003).

Esses espaços de hibridização não implicam o fortalecimento de uma ou outra identidade, mas a desestabilização contínua dos marcadores identitários pela introdução contínua da diferença. Nesse sentido, as diferenças abalam as identidades, descentrando-se constantemente e produzindo novas posições de sujeito, uma multiplicidade de posições que se articulam com o diferente. No entanto, nosso modo de compreensão do mundo ainda se debate nos modelos racionalistas modernos, sem assimilar o caráter da processualidade e produção, no sentido foucaultiano, atribuindo ao mundo um caráter dualista. Evidentemente que isso nos afeta, na medida em que, por exemplo, falamos do violento em oposição ao pacifista, do nazista em oposição ao antinazista, do mocinho, em oposição ao bandido/vilão, enfim, do bem em oposição ao mal. Assim sendo, percebemos as relações de poder envolvidas na própria constituição das diferenças e, como advertem Duschatzky e Skliar (2001), "não sejam estas também consideradas entidades fechadas, essencialmente constituídas". Atribuir uma essência à diferença, do mesmo modo que às identidades, constituiria em fazer permanecer "invisíveis as relações de poder e conflito e se dissolveriam os laços de vinculação entre sujeitos e grupos sociais".

Beatriz e Jane também se referem ao filme "Um lugar no mundo", mas podemos observar que produzem diferentes sentidos a partir desse texto. Beatriz diz não conhecer a procedência do filme, mas acha que poderia ser um documentário, porque a história narrada tem relação direta com a repressão dos anos 70. Ela faz um paralelo com conhecidos seus que foram torturados e mortos nesse período. "O que mais me chamou a atenção no filme foi ver aquela família que, apesar do exílio, não abriram mão de suas convicções políticas e sociais. Acho que esta determinação de até morrer por uma causa é própria da minha geração. Me senti revigorada para insistir numa transformação social em um mundo mais justo e digno". Jane, por sua vez, considerou o filme fantástico porque questiona uma verdade universal, que é o lugar no mundo de cada pessoa. Relata como interessante que esse "lugar" não se referia à questão geográfica, mas significava a razão por que trabalhar, em quem acreditar. "Para mim faz sintonia. Apesar de, aparentemente, não existir mais valores, as pessoas, não as personagens, mas o cara que fez o filme, de uma certa maneira, acredita nisto. Logo, eu saio do cinema modificada, com mais esperança e vontade de lutar".

Salientamos que a proposta deste trabalho não é conhecer o endereçamento dos filmes, até porque seria bastante difícil conhecê-los, pois a 
relação entre a indústria cinematográfica e o público é bastante complexa. Segundo Turner (1997), a última década tem mostrado uma tendência oposta à mídia de massa e a favor de um direcionamento a interesses específicos ou grupos de preferência. Contudo, vale a pena questionar: para qual público foi endereçado o filme "Um lugar no mundo"? Quem sabe para um público que se considere com convicções políticas e sociais justas e com ideais de justiça social. A partir dos significados produzidos por Jane e Beatriz, é possível pensar o cinema como uma possibilidade de transformação social/ individual? Ou, neste caso, apenas reforçou idéias e convicções já existentes, não trazendo elementos novos? Não sabemos se o filme atingiu seu alvo, mas foi premiado no Festival de Gramado em 1993 e até hoje não tem versão em vídeo.

Por outro lado, ainda sobre os modos de endereçamento, Ellsworth (2001) pergunta quem resiste ao endereçamento sedutor e homogeneizador de Hollywood. Assim, não podemos desconsiderar que o cinema narrativo clássico - modelo Hollywood - deve grande parte de sua extraordinária eficácia à sua prática do saciamento afetivo. Norma relata que em duas ocasiões saiu do cinema durante a sessão, pois não agüentou a intensidade da identificação com os personagens. Uma delas foi quando assistiu "Ghost", ${ }^{9}$ pois havia perdido seu marido recentemente e ficou mobilizada sobre a possibilidade de um reencontro com o espírito do marido.

João, por sua vez, considera falso esse tipo de filme, pois o diretor molda, de antemão, a emoção do espectador, não o respeitando como um sujeito criador. Jane considera esse tipo de filme como fechado, pois a proposta (talvez se referisse ao endereçamento) é perceber determinados personagens como vilões e outros como mocinhos, não há espaço para a integração entre o "bem" e o "mal". Ela acrescenta ainda que normalmente o branco tem curso superior, família estruturada e é roubado por um negro sem estudo e com uma mãe prostituta.

O tipo de texto fílmico acima descrito parece ser um bom exemplo do que nos fala Silva (2000), quando alerta que a eleição arbitrária de uma identidade particular como parâmetro para avaliar as outras é um dos processos mais sutis pelos quais o poder se manifesta no campo das identidades e diferenças. Esse processo é eficaz no sentido de fixar posições - as identidades hegemônicas - às quais são atribuídas características positivas, sendo a referência para as outras. Conforme alguns entrevistados, são as dicotomias/binarismos entre, por exemplo, o "bem" e o "mal", impondo sentidos hegemônicos na sociedade. Esse modelo é criticado porque o espectador não entra em crise com seus valores. É o que Lucas considera como um filme pré-moldado. Como diz Pedro, o filme "hollywoodiano" é um pacote, pois qualquer pessoa que tem alguma noção de narração sabe o que move a humanidade. "Então é fácil. Tu cria uma mocinha legal, que trabalha, que batalha, as pessoas se identificam com ela e depois ela pega leucemia e morre. Quem não vai sofrer com isto? É apenas uma catarse, não propicia mudança alguma".

Nesse sentido, evidenciam-se frestas entre o endereçamento fílmico e a resposta social, onde diferentes posições de sujeito estão presentes. É nesse sentido que João diz que os filmes que o levam a pensar são aqueles construídos com a intenção de diálogo com o espectador, chegando ao triângulo de interação - autor, obra e espectador. Refere Truffaut como representante desse estilo. Para João, o cinema tem possibilidade de modificar as pessoas, produzir mudança social. "A arte te propõe justamente questionar, ela propõe questões, e não soluções. Por isto tu sai com questões e, portanto, tu sai transformado. Mas a emoção está presente, com certeza".

Ellsworth (2001) lembra que as experiências de contracinema têm produzido uma série de estratégias para endereçar o público que raramente assiste a filmes "hollywoodianos". O contracinema é supostamente mais aberto e menos manipulativo. Nele há espaço, pelo menos teoricamente, para a espectadora construir a história e produzir expectativas em relação à narrativa.

Outro aspecto relevante é que o impacto da globalização sobre as identidades é uma das características principais para a compreensão espaço-

\footnotetext{
"Ghost - Do outro lado da vida" conta a história de Sam, jovem executivo, que é atacado e morto. O espírito de Sam vê o assaltante que o matou, o segue e descobre que o motivo do assassinato era, de fato, roubar uma senha secreta que dava acesso a um banco de dados e ao saque de grande quantia de dinheiro; uma trama comandada por quem considerava seu melhor amigo. Sam não consegue descansar porque sua namorada corria risco. Sam procura a ajuda de uma vidente para salvar sua namorada do assassino e fazer justiça. A trama enfatiza a história de amor entre o casal, que transcende a morte de Sam (Sinopse feita pela primeira autora).
} 
tempo, à medida que se sente o mundo menor e as distâncias mais curtas (Hall, 2000). Para Veiga-Neto (2000), fenômenos como a compreensão espaçotemporal estão atingindo nossos aparatos psíquicos e cognitivos, de modo a mudar nossa maneira de perceber e significar o cotidiano. Identificamos tal processo em três entrevistadas.

Eu perco a consciência de mim e entro na história. Quando saio do cinema e olho no relógio, sabendo que a sessão iniciou às 19:00, 19:30 e, quando termina a sessão, são 21:30, 21:45!!! Não! Não faz sentido, há uma diferença tão grande do que eu era antes do filme do que sou depois de ver o filme que me parece que não cabe em duas horas, não há espaço temporal. É uma outra dimensão. A minha noção temporal passa a ser a noção temporal da personagem. Como pode, então, ter passado dez anos e eu olhar para o relógio e só se passaram duas horas desde que entrei no cinema. Isso não fecha. (Sandra)

Eu preciso de um tempo para me aclimatar quando saio do cinema. Gosto de ir para a casa caminhando pela rua para, aos poucos, ir saindo da história. O pior é quando entre no cinema de dia e saio de noite. Aí fico mais confusa ainda na questão temporal (Magda). A primeira vez que fui a Paris tive uma sensação de 'déjá-vu'. Eu sentia que já conhecia aquele lugar; quando lembrei que em muitos filmes eu estive lá. Eu conhecia através dos filmes (Norma).

Todos os sujeitos entrevistados disseram que muitos filmes os levam a pensar. As experiências das personagens transformam-se em experiências de vida para Norma, João, Pedro, Beatriz, Paula, Magda e Sandra. Refletir sobre os conflitos suscitados a partir dos filmes, de uma maneira ou outra se relaciona com a vida dos entrevistados. Minha relação com cada filme assistido éúnica, muito pessoal. Eu dialogo com o filme, pois toda minha história de vida está presente quando assisto um filme. É a minha luta interna (Paula). Muitas situações da minha vida pessoal eu pude ponderar, refletir a partir do filme (Magda). Eu fiquei pensando sobre as instituições de forma geral, não apenas na instituição casamento, na maneira como elas se mantêm, se repetem em diferentes épocas e culturas (Pedro). Pensei muito na hipocrisia que é a instituição Igreja (João).

Para a maioria dos entrevistados, os filmes, de forma geral, instigam o intelecto. Desvendar determinadas tramas, acompanhar variados personagens e suas ações exigem raciocínio rápido. Assim, alguns acreditam que o diálogo, a conversa com amigos após o espetáculo cinematográfico possibilita a produção de outros sentidos. Para Norma, por exemplo, o cinema estimula a refletir sobre questões filosóficas, sobre o valor da existência humana; tenta resolver os problemas que os filmes suscitam, questionando e discutindo com outras pessoas.

Finalizando, o presente trabalho pretendeu elucidar algumas questões referentes a uma temática complexa que se refere à relação entre o texto cinematográfico e a experiência do espectador, considerando o campo dos estudos culturais, ou seja, caracterizando o cinema como um artefato da cultura, produzido por e produto de práticas sociais; portanto atravessado por múltiplos significados. Logo, podemos dizer que os sujeitos constroem suas relações e não são somente interpelados por uma ideologia dominante, mas também resistem a ela e se mobilizam produzindo novos sentidos.

\section{Referências}

Bernardes, A.G., \& Guareschi, N. M. F. (2003). A cultura como constituinte do sujeito e do conhecimento. In N. M. F. Guareschi, \& M. E. Bruschi (Org.). Psicologia social nos estudos culturais: Perspectivas e desafios para uma nova psicologia social. Petrópolis: Vozes.

Beylie, C. (1991). As obras primas do cinema. São Paulo: Martins Fontes.

Bruschi, M. (2002). Quando o Titanic encontra o iceberg: $O$ choque entre o amor real e hiperreal em tempos pós-modernos. Santa Cruz do Sul: EDUNISC.

Carrière, J-C. (2006). A linguagem secreta do cinema. Rio de Janeiro: Nova Fronteira.

Donald, J. (1991). Psychoanalysis and cultural theory. Londres: Mcmillan Education.

Duschatzky, S., \& Skliar, C. (2001). O nome dos outros. Narrando a alteridade na cultura e na educação. In: J. Larrosa \& C. Skliar (Org.). Habitantes de Babel: Políticas e poética da diferença. Belo Horizonte: Autêntica.

Ellsworth, E. (2001). Modos de endereçamento: uma coisa de cinema; uma coisa de educação também. In: T. T. Silva. Nunca fomos humanos: No rastro do sujeito. Belo Horizonte: Autêntica.

Escosteguy, A. C. D. (2001). Cartografias dos estudos culturais: Uma versão latino-americana. Belo Horizonte: Autêntica. 
Fabris, E. H. (2000). Hollywood e a produção de sentidos sobre o estudante. In: M. Costa. (Org.) Estudos culturais em educação: Mídia, arquitetura, brinquedo, biologia, literatura, cinema... Porto Alegre: UFRGS.

Fischer, R. M. B. (1999). Identidade, cultura e mídia: a complexidade de novas questões educacionais na contemporaneidade. In L. H. Silva. (Org.). Século XXI: Qual conhecimento? Qual currículo? Petrópolis: Vozes.

Furtado, J. (1992). Um astronauta no Chipre. Porto Alegre: Artes e Ofícios.

Gabler, N. (1999). Vida, o filme. São Paulo: Companhia das Letras.

Gomes, W. B. (1997). A entrevista fenomenológica e o estudo da experiência consciente. Psicologia USP, 8(2), 305-336.

Guareschi, N. M. F. (2003). Identidade, subjetividade, alteridade e ética. In K. S. Ploner, L. R. F. Michels, L. M. Schlindwein, P. A. Guareschi (Org.). Ética e paradigmas na psicologia social. Porto Alegre: ABRAPSO-SUL.
Hall, S. (1997). A centralidade da cultura: notas sobre as revoluções de nosso tempo. Educação \& Realidade, 22(2), 15-46.

Hall, S. (2000). A identidade cultural na pósmodernidade. (5a ed). Rio de Janeiro: DP\&A.

Silva, T. T. (2000). A produção social da identidade e da diferença. In T. T. Silva. (Org.). Identidade e diferença: A perspective dos estudos culturais. Petrópolis: Vozes.

Turmer, G. (1997). Cinema como prática social. São Paulo: Summus.

Veiga-Neto, A. (2000). Michel Foucault e os Estudos Culturais. In M. Costa. (Org.). Estudos culturais em cducação: Mídia, arquitetura, brinquedo, biologia, literatura, cinema. Porto Alegre: UFRGS.
Recebido em: 10/05/2007

Received in: 05/10/2007

Aprovado em: 15/05/2007 